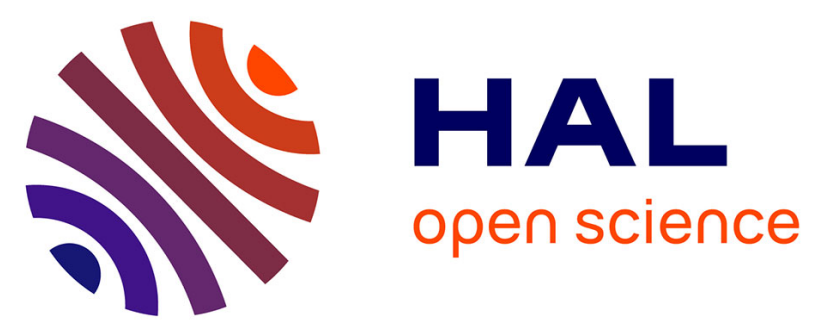

\title{
Fragmentation of two soft cereal products during oral processing in the elderly: Impact of product properties and oral health status
}

Melissa Assad Bustillos, Carole Tournier, Gilles Feron, Sofiane Guessasma, Anne-Laure Reguerre, Guy Della Valle

\section{To cite this version:}

Melissa Assad Bustillos, Carole Tournier, Gilles Feron, Sofiane Guessasma, Anne-Laure Reguerre, et al.. Fragmentation of two soft cereal products during oral processing in the elderly: Impact of product properties and oral health status. Food Hydrocolloids, 2019, 91, pp.153-165. 10.1016/j.foodhyd.2019.01.009 . hal-02625724

\section{HAL Id: hal-02625724 \\ https://hal.inrae.fr/hal-02625724}

Submitted on 21 Oct 2021

HAL is a multi-disciplinary open access archive for the deposit and dissemination of scientific research documents, whether they are published or not. The documents may come from teaching and research institutions in France or abroad, or from public or private research centers.
L'archive ouverte pluridisciplinaire HAL, est destinée au dépôt et à la diffusion de documents scientifiques de niveau recherche, publiés ou non, émanant des établissements d'enseignement et de recherche français ou étrangers, des laboratoires publics ou privés.

\section{(c) (1) $\$$}

Distributed under a Creative Commons Attribution - NonCommerciall 4.0 International 


\section{Fragmentation of two soft cereal products during oral processing in the} elderly: impact of product properties and oral health status

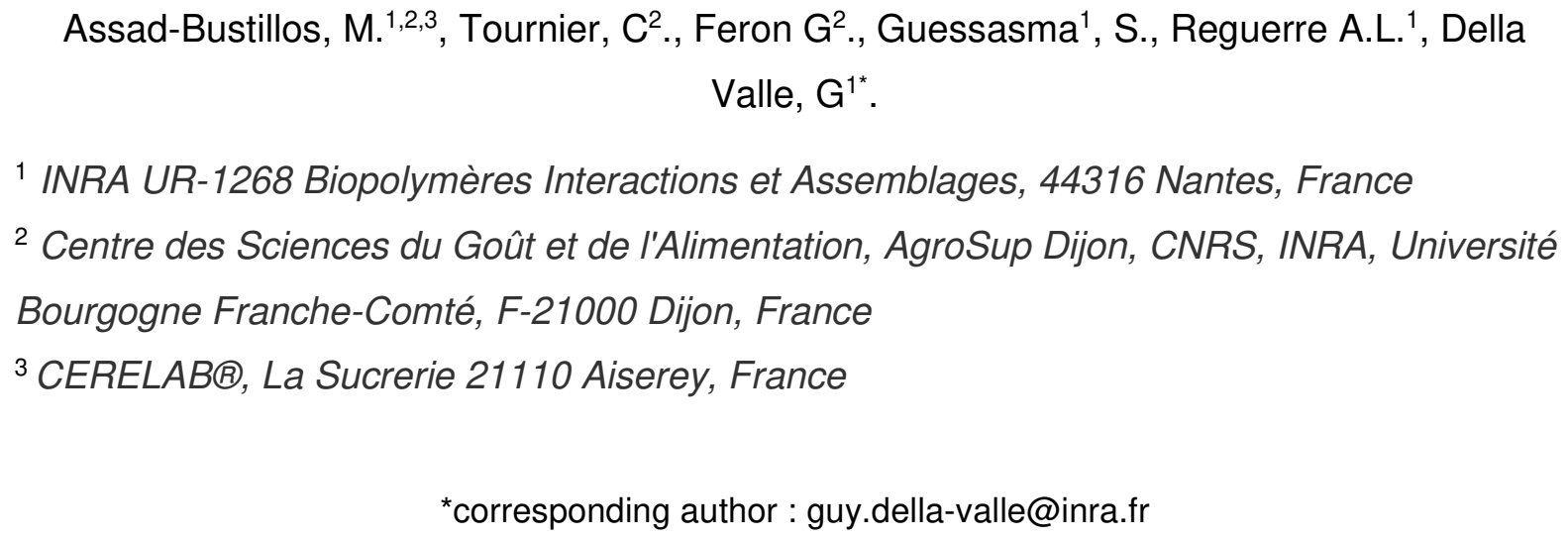

\section{Abstract}

This study investigated the mechanisms of fragmentation leading to bolus formation during chewing in the elderly population for two cereal foods of different compositions and cellular structure: sponge-cake (SC) and brioche (B). For both products, mechanical properties were characterized by uniaxial compression and 3D cellular structure was determined using x-ray micro-tomography. Stress-strain curves showed two distinct ductile-like behaviors: product $B$ underwent plastic deformation, whereas product SC displayed a hyper-elastic behavior. Twenty subjects aged 65 years and over with two different oral health conditions (poor vs satisfactory dental status, variable stimulated salivary flow rate) were asked to consume both products. Bolus particle size was determined at three different chewing stages through image analysis, and the resulting particle size distribution (PSD) curves were fitted by Gompertz model. The model parameters were related to bolus particle heterogeneity and fragmentation, thanks to their correlations with median particle size diameter $D_{50}$ and interquartile ratio $\left(D_{75} / D_{25}\right)$, directly extracted from PSD curves. The use of model parameters allowed discriminating between chewing sequences for both products and revealed different fragmentation patterns: while SC boli exhibited a continuous particle size reduction during chewing, $B$ displayed a combination of fragmentation and agglomeration. In addition, results showed that subjects with a satisfactory dental status produced significantly more degraded boli than those with a poor dental status. These results highlight distinct fragmentation mechanisms for these two soft 
33 products that were interpreted in relation to their differences in composition, structure

34 and mechanical behavior.

\section{Nomenclature}

37 a Gompertz fitting parameter, maximum size value achieved

38 ANSM Acronym for the French 'National Agency of Drugs and Safety'

39 B Brioche

$40 \mathrm{~b} \quad$ Gompertz fitting parameter, slope at the inflexion point

41 c Gompertz fitting parameter, size value at the inflexion point

$42 \quad \mathrm{C} 1 \quad 1 / 3$ of chewing duration, first chewing sequence

43 C2 2/3 of chewing duration, second chewing sequence

$44 \mathrm{D}_{25} \quad$ Particle diameter of first the quartile of the distribution

$45 D_{50} \quad$ Median particle diameter of the distribution

$46 D_{75} \quad$ Particle diameter of the third quartile of the distribution

$47 \quad \mathrm{D}_{75 / 25} \quad$ Interquartile ratio of the particle size distribution

48 DS Dental status

49 E Young's modulus $(\mathrm{kPa})$

50 FOP Food Oral Processing

$51 \quad P \quad$ Poor (Dental status)

52 PSD Particle Size Distribution

53 PFU Posterior Functional Unit

54 S Satisfactory (Dental status)

55 SC Sponge-cake

56 SP Swallowing Point, total chewing duration, third chewing sequence,

57 SSF Stimulated Salivary Flow rate $\left(\mathrm{mL} \cdot \mathrm{min}^{-1}\right)$

$58 \quad \mathrm{XR}-\mu \mathrm{CT} \quad \mathrm{X}$-Ray Micro-Computed Tomography 


\section{Introduction}

The physiological deterioration that accompanies ageing, together with the fact that the population aged 60 and over is expected to nearly triple by 2050 (United Nations, 2002), have increased the demand for foods with optimum texture design that are nutritious, safe and enjoyable (Chen, 2016; Schwartz, Vandenberghe-Descamps, Sulmont-Rossé, Tournier, \& Feron, 2017).

Peleg early pointed out the need for understanding the relationship between the mechanical and geometrical properties of a food and its perceived texture in order to provide guidelines to develop specific products targeted for the elderly (Peleg, 1993). Since then, advances in the understanding of food oral processing (FOP) have been extensively reviewed (Chen, 2009, 2014, 2015) and the importance of structure and mechanical properties of foods in the bolus formation mechanisms has been highlighted (Gao, Wang, Dong, \& Zhou, 2017; Pascua, Koç, \& Foegeding, 2013; Witt \& Stokes, 2015), as well as in the perception of flavor (Panouillé, Saint-Eve, Déléris, Le Bleis, \& Souchon, 2014) and texture (Devezeaux de Lavergne, Derks, Ketel, de

76 Wijk, \& Stieger, 2015; Gao, Ong, Henry, \& Zhou, 2017). These works have improved 77 the understanding of texture by combining the studies of bolus formation mechanisms with the structural and mechanical properties of foods. The perception of texture is recognized as a dynamic process and does not depend only on the initial

80 food properties, which govern the early stages of mastication (Kim et al., 2012;

81 Young, Cheong, Hedderley, Morgenstern, \& James, 2013), but also on bolus properties towards the middle and the end of oral processing (Devezeaux de

83 Lavergne, van de Velde, \& Stieger, 2017; Jourdren, Saint-Eve, et al., 2016). The 
characterization of bolus properties has thus become crucial to the understanding of FOP and perception mechanisms. This approach has been poorly addressed in the elderly, despite that such knowledge could bring new opportunities to develop food products specifically targeted for this population. Recently, we studied the relationships between sensory perception, food oral processing and bolus properties for two cereals products, namely sponge-cake and brioche, in elderly subjects varying in dental status and salivary flow rate (Assad-Bustillos, Tournier, Septier, Della Valle, \& Feron, 2017). We developed a phenomenological model predicting the evolution of bolus apparent viscosity during oral processing. Viscosity was found to decrease with the theoretical amount of saliva absorbed, expressed as the product of chewing time by the stimulated salivary flow rate, irrespectively of the dental status of the subjects (Assad-Bustillos et al., 2017). However, the model displayed some dispersion, likely because the contribution of the particle size distribution of bolus fragments (PSD) was not taken into account.

The PSD of foods during oral processing has been early recognized as a crucial factor in bolus formation (Hoebler, Devaux, Karinthi, Belleville, \& Barry, 2000; Olthoff, Van Der Bilt, Bosman, \& Kleizen, 1984; Peyron, Mishellany, \& Woda, 2004), and has been identified as a key parameter in the triggering of swallowing (Jalabert-Malbos, Mishellany-Dutour, Woda, \& Peyron, 2007; Peyron et al., 2011). Many studies have attempted to describe the comminution process of food materials after chewing by using mathematical models that consider the probability of a particle of being selected and its degree of fragmentation, which in turn depend on other factors such as its shape and mechanical properties (Lucas \& Luke, 1983; van der Bilt, Olthoff, van der Glas, van der Weelen, \& Bosman, 1987; van der Glas, Kim, Mustapa, \& Elmanaseer, 2018; van der Glas, van der Bilt, \& Bosman, 1992). To this extent, there 
109 have been attempts to relate the degree of fragmentation of several foods to their 110 mechanical properties (Agrawal, Lucas, Prinz, \& Bruce, 1997; Chen, Khandelwal, Liu, 111 \& Funami, 2013; Lucas, Prinz, Agrawal, \& Bruce, 2002). From these studies, it 112 appears that the median particle size $\left(D_{50}\right)$ of the bolus before swallowing is inversely 113 related to the food hardness obtained from instrumental measurements performed by 114 uniaxial compression. However, these observations seem to be limited to foods that 115 exhibit brittle facture, meaning that they break in their elastic domain. As pointed out 116 by Gao, Wang, et al. (2017), there is a lack of similar studies concerning fracture in 117 ductile (also referred as soft) food materials, which are able to resist high levels of 118 plastic deformation before breaking (e.g. bread or cakes).

119 As far as we know, the only cereal food exhibiting ductile behavior for which PSD 120 after chewing has been studied and modelled is bread. Different methods have been 121 used to characterize the PSD, such as drying, sieving and weighing the recovered 122 fractions. Image acquisition - based on optical scanning, camera and/or laser 123 diffraction for small particles $(\leq 1 \mathrm{~mm}$ ) (Jourdren, Panouillé, et al., 2016; Le Bleis, 124 Chaunier, Della Valle, Panouillé, \& Réguerre, 2013; Pentikäinen et al., 2014) (Gao, 125 Wong, Lim, Henry, \& Zhou, 2015; Hoebler et al., 1998, 2000) - have been used to 126 provide a more accurate quantitative analysis. The diversity of methods used has 127 made it difficult to compare results between studies. Yet, all of them concluded that 128 there is a general decrease of the median particle size (D50) over time, and Jourdren, 129 Panouillé, et al., 2016 also reported an increase in bolus heterogeneity, which they 130 chose to assess by the interquartile ratio $\left(D_{75} / D_{25}\right)$. In contrast, the influence of the 131 initial bread structure in the PSD has not been extensively studied, and so far the 132 reported results lack of consensus. For instance, Pentikäinen et al. (2014) showed 133 that rye wholegrain breads, which featured denser structures and thicker cell walls 
134 than traditional wheat bread, led to boli that contained smaller particles. Yet, in a

135 similar study, Le Bleis, Chaunier, Montigaud, \& Della Valle (2016) found no

136 significant effect of structure in the $D_{50}$ of boli from fiber-rich bread with different

137 densities. In general, inter-individual variability is considered to have a large influence

138 on oral processing and bolus properties (Panouillé, Saint-Eve, \& Souchon, 2016).

139 However, when it comes to particle size, the impact of physiology has rarely been

140 taken into account (Fontijn-Tekamp, van der Bilt, Abbink, \& Bosman, 2004; Hoebler

141 et al., 1998; Peyron et al., 2004). Furthermore, there is a lack of focus on the elderly

142 population, whose oral health is frequently deteriorated due to tooth loss and

143 decreased salivary flow rate (Laguna, Aktar, Ettelaie, Holmes, \& Chen, 2016; Ship,

144 1999; Vandenberghe-Descamps et al., 2016).

145 Hence, considering the various aspects involved in food fragmentation and bolus

146 formation, the objectives of this study were, in the first place, to accurately describe

147 and assess the fragmentation process during the chewing of two soft cereal foods

148 with different composition and structure in an elderly panel; and secondly, to assess

149 the impact of the oral health status of the participants in the said foods' fragmentation

150 process. In this purpose, we have fully characterized the PSD of sponge-cake (SC)

151 and brioche (B) boli collected after three chewing stages from a group of elderly

152 subjects. Additionally, the data was fitted with a mathematical model in order to be

153 able to extract as much information as possible and avoid single parameter

154 comparisons. With this information, the influence of the dental status (DS) and

155 salivary flow rate (SSF) of the elderly on the PSD of the boli was evaluated.

\section{2. Materials and Methods}


158 The sponge-cake and brioche used in this study were provided by CERELAB®,

159 France. Their composition is detailed in Table A (Appendix).

160 Their instrumental texture was defined by their density, 3D cellular structure and 161 mechanical behavior. The product density was measured by the rapeseed 162 displacement method.

163 The three-dimensional cellular structure was determined by X-ray micro-computed 164 tomography $(\mathrm{XR}-\mu \mathrm{CT})$, using a compact table-top system Skyscan 1174 (Bruker 165 microCT, Belgium). A cylindrical sample of each product with a diameter of $2 \mathrm{~cm}$ and 166 a height of $3 \mathrm{~cm}$ was prepared with a steel cutter and placed on a rotating plate while 167 the X-ray beam passed through. A CCD camera with a resolution of $1304 \times 1304$ 168 pixels was used to acquire the $2 \mathrm{D}$ radiographic images. The exposure time was 2000 $169 \mathrm{~ms}$, and the pixel size was adjusted to $22 \mu \mathrm{m}$. Two images were taken per rotational 170 step (every $0.5^{\circ}$, until $360^{\circ}$ ) and were averaged. The projections were then 171 reconstructed to obtain cross-sectional images using the NRecon reconstruction 172 software (Bruker microCT, Belgium). Reconstructions were based on the Feldkamp 173 cone-beam algorithm (Feldkamp, Davis, \& Kress, 1984). After reconstruction, a stack 174 of 1000 images in TIFF format was obtained for each sample. 3D images were 175 therefore composed of $1304 \times 1304 \times 1000$ voxels, coded on an 8 -bit grey-scale. One 176 replication was made for each product, for a total of four independent 3D images 177 generated. From the images, the granulometric curves, that lead to cell wall size and 178 cell wall thickness values, were calculated by using mathematical morphology 179 operations (Serra, 1982). A series of openings of increasing size (image sieving) 180 was performed on the features of interest and the sum of the volume occupied by the 181 sieved particles, either cells or walls, was computed at each step. The results were 182 expressed as the plot of the cumulative volume (\%) of the particle vs the particle 
183 diameter $(\mu \mathrm{m})$. In addition, the relative density (D) was calculated by dividing the

184 volume occupied by the cell walls by the total volume of the sample, and the void 185 fraction $(\mathrm{VF})$, or porosity $(\mathrm{P})$, was calculated as the complementary fraction $\mathrm{D}(1)$

$$
P=V F=1-D
$$

187 The mechanical properties were determined by uniaxial compression test. A circular

188 steel cutter was used to prepare cylindrical samples with a diameter of $40 \mathrm{~mm}$ and a 189 height of $30 \mathrm{~mm}$. Both products were subjected to uniaxial compression using a universal testing machine (Adamel Lomarghy, France) equipped with a $1 \mathrm{kN}$ load 191 cell. The testing was performed with a cross head speed of $50 \mathrm{~mm} / \mathrm{min}$ until $66 \%$ in 192 height reduction between parallel plates. Five replicates were performed for each 193 food sample. Results were expressed as the stress versus strain plot, from which 194 Young's modulus $(E)$, and the critical stress $\left(\sigma_{c}\right)$, when applicable, were measured. $E$ was calculated from the initial slope within the linear elastic domain, while $\sigma_{c}$ was defined as the stress value at the end of the linear domain.

\subsection{Panel composition}

198 Twenty subjects (9 men and 11 women, aged 65-82 years, average $72 \pm 5$ years) 199 participated in the study. Their dental status (DS) was assessed by determining the 200 number of Posterior Functional Units (PFU's), allowing their classification within two 201 groups: poor ( $\leq$ 4PFU's) and satisfactory ( $\geq 7$ PFU's) DS. Additionally, their salivary 202 flow rate in $\mathrm{mL} \cdot \mathrm{min}^{-1}$ under mechanical stimulation (SSF), was determined for each 203 subject. The chewing duration up to the swallowing point (SP) was determined for 204 each subject and product through video recording. These techniques were previously 205 used and detailed by Assad-Bustillos et al. (2017). The results obtained for the 206 average SSF and the SP of all participants, including their standard deviation, are 207 recalled in Table B (See Appendix). All subjects agreed on the content of the study 
and signed informed consent. This study was approved by the local ethical

209 committee (CPP Est-I) and the French National Agency of Drugs and Safety (ANSM)

210 (ID RCB n²016-A00916-45).

2.3 FOP assessment and bolus collection

212 Mouthfuls of $20 \mathrm{~cm}^{3}$ of each product were cut right before the experimentation. Each

213 member of the panel was asked to eat a mouthful and to expectorate the generated

214 bolus at three different chewing sequences that were defined according to each

215 individual's swallowing point, as described in detail by Assad-Bustillos et al. (2017).

216 The chewing stages were defined as follows: $1 / 3$ of the total chewing duration (C1),

$2172 / 3$ of total chewing duration (C2) and just before the swallowing point (SP, total

218 chewing duration). At each chewing sequence, one bolus was generated. The bolus

219 was suspended immediately after collection in $150 \mathrm{~mL}$ of glycerol (VWR International,

220 USA) inside a plastic container with a resealable screw-lid and was agitated at room

221 temperature for $1 \mathrm{~h}$ using a magnetic stirrer at $170 \mathrm{rpm}$ to allow particle dispersion

222 without damaging bolus structure, according to the procedure set up by Le Bleis et al.

223 (2013). The boli were stored at $4^{\circ} \mathrm{C}$ until the moment of analysis.

224 Bolus particle size analysis

225 Before analysis, the boli suspended in glycerol were re-agitated at a rotation speed

226 of $170 \mathrm{rpm}$ during $80 \mathrm{~min}$ at $20^{\circ} \mathrm{C}$ in a water bath (Julabo SW23, Germany) to ensure

227 homogenous particle dispersion for all samples. Bolus particles were carefully placed

228 in a Petri dish (diameter $=5.5 \mathrm{~cm}$ ) that was placed over a matte dark background and

229 was backlighted through an optical fiber ring (Schott DCR IV, USA) placed

230 underneath, as described by Le Bleis et al. (2013). The images were acquired in gray

231 level with a monochrome CMOS video camera (EXO SVS-250MGE Vistek,

232 Germany). For each bolus, at least $90 \%$ of the total volume was characterized, with a 
233 minimum of 10 images per bolus, for a total of 1200 images. Images were saved in

234 TIFF format as matrices of $2448 \times 2048$ pixels, with a pixel size of $15 \mu \mathrm{m}$. Image 235 analysis was performed with Matlab software (Mathworks 2016b, USA). Particle size 236 distribution (PSD) was obtained using operations of mathematical morphology by 237 performing a series of openings of increasing size (image sieving) as described 238 above for the 3D images. The results were expressed as a plot of the cumulative 239 area (\%) of the particle vs the particle diameter in $\mathrm{mm}$, also named PSD curve.

\subsection{Data treatment and Statistical analysis}

241 For each subject and each chewing sequence (C1, C2, SP), the median equivalent 242 diameter $\left(D_{50}\right)$ and the interquartile ratio $\left(D_{75} / D_{25}\right)$ were derived from the PSD curve. 243 The ratio $\left(D_{75} / D_{25}\right)$ characterizes the heterogeneity of the bolus (Jourdren, Panouillé, 244 et al., 2016). Moreover, to ascertain their description, all PSD ( $n=120)$ were fitted with 245 a three-parameter Gompertz model (2). Gompertz model has been previously used 246 to model the PSD of soils (Botula, Cornelis, Baert, Mafuka, \& Van Ranst, 2013;

247 Esmaeelnejad, Siavashi, Seyedmohammadi, \& Shabanpour, 2016), in vitro 248 degradability of rumen from cereal meals (Gallo, Giuberti, \& Masoero, 2016) and to model the porosity kinetics of bread dough during proofing (Kansou et al., 2013). In this study, it is used to model the PSD of food particles after chewing:

$$
A=a \times \exp (-\exp (-b \times(p-c)))
$$

252 Where $\mathrm{A}$ is the fraction of cumulated particles area (\% of total particle area), $\mathrm{p}$ is the particle size (mm), "a", "b" and "c" are parameters obtained by fitting. Parameter "a" is 254 an approximation of the maximum cumulated area, "b" is the slope of the size 255 distribution curve at the inflection point, and parameter "c" is the particle size at the 256 inflection point. Curve fittings were performed using the modules "NumPy" and 257 "SciPy" from Python v.3.2.5.1 software (Python Software Foundation). 
259 A one-way ANOVA was performed to determine the differences of structural and 260 mechanical properties between the two products. In order to investigate differences 261 between products at each chewing stage, a repeated measures ANOVA (product + 262 subject + chewing sequence) was carried out for the median particle size $D_{50}$, 263 interquartile ratio $D_{75} / D_{25}$ and Gompertz parameters ("a", "b", "c,"), with the chewing 264 sequence as repeated factor. Additionally, a one-way ANOVA was carried out for 265 each product to investigate differences between chewing sequences. Furthermore, 266 to investigate the impact of oral health status, a three-way ANCOVA (Analysis of 267 covariance) model with level 2 interactions was applied for each product (chewing 268 duration + dental status + stimulated salivary flow + dental status $\times$ stimulated salivary 269 flow + dental status $\times$ chewing duration + stimulated salivary flow $\times$ chewing duration).

270 For every statistical procedure, a significance level of $\alpha=0.05$ was used and results 271 reported according to Type III sum of squares. The Student-Newman-Keuls test was 272 used for post-hoc comparison tests. All statistical analyses were performed with 273 XLSTAT software (v.2016 18.06, Addinsoft, USA).

\section{3. Results and discussion}

\subsection{Structure and mechanical properties of the two cereal foods}

276 The values of structural and mechanical properties of both products are reported in

277 Table 3, together with their standard deviation. Not surprisingly, both foods show 278 distinct structural features due to their different composition and process. The first 279 indicator of these differences is density, where sponge-cake (SC) showed a lower 280 value $\left(\rho^{*}=0.21 \mathrm{~g} \cdot \mathrm{cm}^{-3}\right)$ than brioche $(B)\left(\rho^{*}=0.33 \mathrm{~g} \cdot \mathrm{cm}^{-3}\right)$. This may be the reason 281 why the cellular structure of SC displayed larger bubbles, or gas cells, while B 282 displayed smaller cells (Fig.1 a, b). From 3D image analysis, the relative density (D) 
283 values $(D=0.21$ for $S C$ and 0.31 for $B$ ) agree with those determined using the 284 rapeseed displacement method (Table 1).

285 From the granulometric curves (Fig.1 c), it can be seen that cell wall size distributions 286 of both foods are close to each other with a median size $\left(D_{50}\right)$ value of $\approx 100 \mu \mathrm{m}$ and $287 \approx 120 \mu \mathrm{m}$ for SC and B, respectively (Table 1). Regarding the voxel size, i.e. $22 \mu \mathrm{m}$, 288 these two values can be considered not significantly different. Conversely, the cells 289 were found significantly larger for $S C$ than $B$, with a median size of $\approx 300 \mu$ m and $290 \approx 200 \mu \mathrm{m}$ respectively (Table 1 ). Hence, in line with the difference of density, the main 291 difference in cellular structure between products comes from the cell size.

292 Differences between products with regards to their mechanical behavior can also be 293 observed from the stress-strain curves obtained by compression tests (Fig.2). B 294 behaves like an elasto-plastic material, i.e. that displays inelastic permanent deformation after unloading. Its behavior features a linear elastic part, followed by a plateau-like stage where stress is kept constant due to cell wall buckling and yielding, 297 then followed by a continuous increase of stress reflecting material densification. 298 Conversely, SC behaves like a hyper-elastic material, i.e. it deforms elastically over a 299 large range of loading levels, and its behavior is marked by a continuous increase of 300 the stress until densification. The former behavior has been widely reported in baked 301 products including different types of bread and sponge-cake (Attenburrow, 302 Goodband, Taylor, \& Lillford, 1989; Hibberd \& Parker, 1985; Scanlon \& Zghal, 2001; 303 Wang, Austin, \& Bell, 2011). Contrarily, the latter has been rarely observed in starch 304 based food materials (Guessasma \& Nouri, 2015; Mohammed, Tarleton, 305 Charalambides, \& Williams, 2013). Both behaviors may be assigned to ductile foams, i.e. products that have a large porosity and a cellular structure with cell wall material in the rubbery state, as described by Gibson \& Ashby (1997). 
308 The values of Young's moduli $(E)$, for both products, and critical stress $\left(\sigma_{c}\right)$ for B are 309 reported in Table 1 . B had a higher value of $E(20 \mathrm{kPa})$ than $\mathrm{SC}(5 \mathrm{kPa})$. This 310 difference may be attributed mainly to the density differences, in line with Gibson \& 311 Ashby's (1997) scaling law for solid foams.

312 Finally, these values of structural and mechanical properties are in the range of those

313 found for other baked products like breads (Besbes, Jury, Monteau, \& Le Bail, 2013;

314 Gao et al., 2015; Pentikäinen et al., 2014; Van Dyck et al., 2014) and cakes 315 (Bousquières, Michon, \& Bonazzi, 2017; Dewaest et al., 2017; Lassoued, Babin, 316 Della Valle, Devaux, \& Réguerre, 2007; Sozer, Dogan, \& Kokini, 2011). Median cell 317 size ( $\left.D_{50}\right)$, however, was on the lower edge of the interval $[300,1600 \mu \mathrm{m}]$ 318 encountered in these studies. This could be explained by the high levels of fat of both products, which, according to Brooker (1996), lead to finer crumb grains.

3.2 Particle size distribution (PSD) of the cereal food boli: analysis and curve fitting

322 Cumulative particle size distributions of food boli (PSD) were determined by 323 quantitative image analysis for each subject, each chewing sequence and each 324 product (Fig. 3). The average values for all subjects of the median diameter (D50) and 325 the interquartile ratio $\left(D_{75} / D_{25}\right)$, an indicator of bolus heterogeneity (Jourdren, 326 Panouillé, et al., 2016), were extracted from the PSD curves and are shown in Table 3272 for both products. Firstly, B boli had significantly higher D50 values than SC at all 328 chewing stages. Secondly, for SC, D50 was significantly reduced over the chewing 329 sequences. B boli, on the other hand, did not show any significant variation of D50 330 throughout the chewing stages. Also, $D_{50}$ of $B$ boli showed a higher inter-individual 331 variability than $S C$, as reflected by the higher standard deviation. In addition, $D_{75} / D_{25}$, 332 decreased significantly for SC, meaning these boli tend to reduce particle size 
333 towards the same value as mastication progresses. Conversely, this value increased

334 significantly for B boli, meaning particle heterogeneity becomes higher over the 335 chewing sequences. The variations over time of $D_{50}$ and $D_{75} / D_{25}$ for all subjects and 336 both products are shown in Fig. 4. This figure confirms the previous analysis and 337 clearly depicts the scattered variations of $D_{50}$ for B and illustrates the complexity of 338 chewing mechanisms in this product, likely combining fragmentation and 339 agglomeration of food particles.

340 These results also show that using a single parameter from the PSD, such as $D_{50}$, is 341 not always sufficient to understand the complex variations of particle size during 342 mastication. Therefore, PSD curves were fitted with the Gompertz three-parameter 343 model described in 2.5 (Fig.3), in order to integrate the whole information brought by 344 these curves and determine if $D_{50}$ and $D_{75} / D_{25}$ conveniently describe those. The 345 average values of the fitting parameters obtained for both products and each 346 chewing sequence are shown in Table 2. Out of 120 fitted PSD curves, 112 of them 347 had a satisfactory fitting $\left(R^{2} \geq 0.9\right), 2$ had a low quality fitting $\left(0.6 \geq R^{2} \geq 0.8\right)$, and 6 had 348 an unsuccessful fitting $\left(R^{2} \leq 0.5\right)$ (cf. Appendix).

349 As expected from cumulative curves (Fig.3), "a" coefficient values remain unchanged, 350 close to 100 for all products and chewing sequences, suggesting that the 112 PSD 351 curves of food boli can be described by only the two coefficients "b" and "c", whose 352 values differ significantly between products for almost every chewing sequence. 353 Coefficient "b" varies significantly between chewing sequences for SC, and 354 coefficient "c" does it for both products. Furthermore, it was found that "c" is positively 355 correlated to $D_{50},\left(R s c=0.94, R_{B}=0.95 p<0.0001\right)$, and the regression line is closed 356 to the bisector. Conversely, "b" is negatively correlated to $D_{75} / D_{25},\left(R s c=-0.65, R_{B}=-\right.$ $3570.49 \mathrm{p}<0.0001$ ) (Fig. 5). The correlation is particularly satisfactory for both factors in 
358 the case of SC. These results confirm that the two coefficients describe completely

359 the variations of particle size boli during chewing. Furthermore, they suggest that the 360 variations of "c" reflect the mean size of bolus particles, and hence their degradation 361 degree: the smaller the "c" value, the more degraded the bolus. Conversely, "b" can 362 be considered as an index of homogeneity of the particle size distribution, at least for 363 SC. These two parameters of the PSD model will be used in the following section to 364 analyze the effect of the oral health status on bolus fragmentation.

365 The remaining 8 "misfit" PSD curves came from boli that featured a high percentage 366 of large size particles, which introduced jaggedness to the distributions, hence 367 making them difficult to fit (see Fig. 3 c,d). Interestingly, all of these boli came from B 368 and belonged to either the second chewing sequence (C2) or the swallowing point 369 (SP). This means the large particles were present by the end of mastication, 370 therefore suggesting agglomeration. Indeed, a closer examination of the PSD curves 371 and bolus images revealed the presence of three fragmentation patterns (cases I, II 372 and III). Case I consists of an overall decrease of particle size over the chewing 373 sequences and an increase in the number of small particles. It is represented by a 374 curve translation towards smaller sizes (Fig 3 a,b). All of the sponge-cake (SC) boli 375 followed case I pattern, with more than $90 \%$ of overall particles with a size lower than $3766 \mathrm{~mm}$ (Fig. 6a). This trend was followed for brioche (B) boli for 10 out of 20 377 individuals (Fig. 6b). Out of the remaining 10, 2 showed a clear pattern of 378 agglomeration (case II), which is represented by a translation of the curve towards 379 larger size is with a jagged appearance due to large size particles (>14mm) (Fig. 3c), 380 and is depicted by an increase in particle size during chewing until bolus becomes a 381 single paste-like particle (size $\approx 20 \mathrm{~mm}$ ) (Fig. $6 \mathrm{c}$ ). For 8 cases, a non-monotonous 382 variation was found, with two possibilities: either an increment in particle size during 
383 C2 followed by an immediate decrease of particle size at the SP (Fig. 6d), or a

384 decrease in particle size in C2, followed by an increase of particle size in SP (not 385 shown), suggesting a pattern combining agglomeration and fragmentation (case III).

386 Actually, there was no particular relationship between the individual physiology and 387 the agglomeration patterns, for these 10 specific cases as illustrated by Table D

388 (Appendix).

3.3 Influence of oral health status on bolus fragmentation / agglomeration patterns

391 The influence of the oral health status on particle size distributions and model 392 parameters was investigated through ANCOVA model and the results are shown in 393 the present section. In spite of large variations of SSF, from 0.3 to $3.84 \mathrm{~mL} / \mathrm{min}$ 394 overall (see Table B in Appendix), no significant effect of salivary flow rate (SSF) on 395 D50 or PSD model parameters was found for any of the products. For sponge-cake 396 (SC), a significant relationship between dental status (DS) and median particle 397 diameter $\left(D_{50}\right)$ was identified $(p<0.05)$. The normalized coefficient of the model for the 398 satisfactory DS group $(\beta \mathrm{s})$ was -0.8 . This result means that individuals with a 399 satisfactory DS produced boli with lower D50 values than those with a poor DS. The 400 same result was obtained when performing the analysis with "c" Gompertz coefficient 401 instead of $D_{50}(p<0.001, \beta s=-1.0)$. However, in this model, a significant interaction 402 between chewing duration and DS was found $(p<0.01)$, where $\beta \mathrm{s}=0.6$. This positive 403 value may reflect the limited size reduction ( $D_{50} \geq 0.15 \mathrm{~mm}$ ), illustrated in Fig.4a, for 404 longer chewing duration and satisfactory DS. Conversely, for brioche (B), no 405 significant effect of DS was found for $D_{50}$. A different result was obtained, 406 nonetheless, with "c", where DS had a significant effect $(p<0.01, \beta$ s $=-0.3)$, meaning 407 this parameter is lower for subjects with a satisfactory DS. This also means that, 
contrary to $\mathrm{D}_{50}$, "C" coefficient allows differentiating B boli based on the DS of

409 subjects, and it confirms that Gompertz model parameters more completely account

410 for PSD variations than directly extracted characteristics such as $D_{50}$. Neither $D_{75} / D_{25}$

411 nor "b" showed significant relationships with DS or SSF, suggesting that, in the case

412 of these soft cereal foods, bolus particle heterogeneity is independent of the oral

413 health status. Moreover, no particular trend was found with regards to the number of

414 agglomeration cases $(n=10)$ and their distribution according to DS or SSF. More

415 importantly, since no relationship with SSF was found for any of the studied

416 parameters, it is clear that fragmentation does not depend on salivary flow.

\subsection{Overall discussion}

418 Our results demonstrate that the Gompertz model accounts for the variability the 419 particle size distribution (PSD) of food particles, and that the two parameters, "b" and "c" that result from it, are sufficient to discriminate between products and chewing 421 sequences. Therefore, they are worth to be related to bolus and chewing 422 characteristics. Also, the analysis of the quality of fit resulted in a quick way to detect 423 atypical data, allowing the identification of different fragmentation patterns in the two 424 studied foods, as discussed in section 3.2. While Sponge-cake (SC) boli featured a 425 monotonous and continuous fragmentation pattern (case I), Brioche (B) boli 426 displayed three different fragmentation patterns (cases I, II and III), including 427 agglomeration in $50 \%$ of cases. Moreover, as observed in our previous study (Assad428 Bustillos et al., 2017), B boli were perceived as sticky and pasty, which is in 429 agreement with the observed agglomeration patterns observed in the present work.

430 Case I type of behavior has already been observed in other ductile cereal products, 431 like bread (Jourdren, Panouillé, et al., 2016; Le Bleis et al., 2016). However, patterns 432 combining fragmentation and agglomeration during bolus formation, such as cases II 
433 and III, have only been reported for brittle cereal products (Rodrigues, Young, James,

434 \& Morgenstern, 2014; Young et al., 2013; Yven, Guessasma, Chaunier, Della Valle,

435 \& Salles, 2010). Yven et al. (2010) suggested that the transition from fragmentation

436 to agglomeration during chewing is linked to a transition of the material from brittle to

437 ductile. Such shift also seems to depend on the initial structural and mechanical

438 properties of the food, as it occurred faster and was more abrupt for the densest and

439 hardest foods (Young et al., 2013; Yven et al., 2010). Therefore, agglomerative

440 patterns are somehow associated to ductile behavior, and in our case, the structural

441 and mechanical differences between the studied foods are probably responsible for

442 the observed fragmentation mechanisms. Among the two products, B featured a

443 denser structure and higher values for mechanical properties; it also displayed an

444 elasto-plastic behavior, which is known for its low energy dissipation. This means the

445 material can undergo high levels of strain with a relatively small increase in stress. As

446 a result, more energy and effort are needed to break down this type of materials, as

447 much as shearing to allow cell wall breakage. A higher masticatory effort could

448 translate in a longer chewing duration, but also in a bolus formed of larger particles

449 (Gao, Tay, Koh, \& Zhou, 2018). In our case, the chewing duration of the two products

450 was similar, yet, the combined effect of a denser structure and elasto-plastic nature

451 could partially account for the higher bolus particle size and agglomerative behavior

452 of $B$.

453 Conversely, the mechanical behavior of SC was best described by a hyper-elastic

454 constitutive law. Like previously mentioned, this behavior is characterized by a 455 continuous non-linear increase of stress that results from reversible structural 456 modification during compressive loading. However, SC cannot be considered as a 457 true hyper-elastic material since it is neither isotropic nor incompressible (Mihai \& 
458 Goriely, 2015). From a microstructural point of view, this behavior can be explained

459 by the rearrangement of cells and their modification when loading is applied. In SC, it 460 is clear that failure mechanisms are dominated by irreversible non-plastic 461 deformation. Further experiments using high-resolution 3D image acquisition under 462 compression and shearing would be useful to better understand these mechanisms. 463 Still, it is possible to state that the generated cell wall damage of SC is higher than B 464 at the early stages of compression, thus leading to an increase of stress at a faster 465 rate. This hypothesis would explain why SC was broken down into smaller particles 466 without increasing the chewing duration. Therefore, at product level, differences in 467 fragmentation patterns can be partially explained by the mechanical behavior of the 468 two foods.

469 At the individual level, part of the variability observed in the bolus particle size was 470 explained by the physiology and particularly the dental status (DS) of the elderly 471 subjects. As discussed in section 3.3, a significant relationship between a satisfactory 472 DS and a lower bolus particle size was evidenced for both products. It was also seen 473 that in spite of large variations of stimulated salivary flow rate (SSF), this variable is 474 not involved in the fragmentation process, unlike other bolus properties like hydration 475 or viscosity (Assad-Bustillos et al., 2017). Additionally, no correlation between 476 agglomeration and DS or SSF was found. Still, it is likely that other physiology 477 variables are involved in this mechanism, since agglomeration only occurred in $50 \%$ 478 of the cases. According to Prinz \& Lucas (1997), the tongue is highly involved in the 479 packing and pressing of bolus particles against the palate. In the elderly, the tongue 480 and cheek muscles that are associated with this function may be altered inducing 481 changes in tongue activity and bite force (Laguna, Sarkar, \& Chen, 2015; Laguna et 482 al., 2016; Laguna, Sarkar, Artigas, \& Chen, 2015; Peyron, Woda, Bourdiol, \& 
483 Hennequin, 2017). Hence, physiological variables such as tongue pressure, tongue 484 muscular activity and bite force may are worth to be taken into account in future 485 studies in order to better understand these mechanisms in the elderly. Finally, from the ANCOVA analysis performed with Gompertz model parameters, we found that DS has a significant impact on fragmentation. This result suggests that

Gompertz parameters provide more information about the fragmentation properties of the food bolus than the parameters extracted directly from the distribution curves.

Moreover, modelling the PSD should facilitate the implementation of numerical

491 models based on discrete elements in similar conditions to chewing, like the one 492 proposed by Hedjazi, Martin, Guessasma, Della Valle, \& Dendievel (2014).

\section{Conclusion}

494 By using quantitative image analysis of food boli taken at different steps of oral processing, we demonstrated that particle size distribution could be usefully fitted by Gompertz model. This model allows interpreting the food particle size evolution the 497 chewing process in terms of bolus particle heterogeneity and fragmentation. We 498 identified and described different fragmentation mechanisms for two soft cereal 499 products differing in their initial structure and mechanical properties during oral 500 processing in the elderly: sponge-cake was regularly fragmented, whereas brioche 501 agglomerated. These mechanisms were explained the compressive mechanical 502 behavior and intrinsic cell wall properties of the food products. Finally, we put into 503 evidence the importance of the elderly dental status in the fragmentation of both 504 foods, while salivary flow rate was not found to be involved in this process. This study 505 also highlights the need to understand the chewing process of cereal products as a 506 combination of fragmentation and agglomeration mechanisms, and spurs the use of 
507 mathematical models to describe the evolution of particle size in order to be able to

508 take this complexity into account.

509 Acknowledgements

510 This work was funded and supported by AlimaSSenS project (ANR- 14-CE20-0003).

511 The authors thank Sylvie Chevallier from ONIRIS Nantes for her assistance in 3D

512 image acquisition and analysis.

513

514

References

516

Agrawal, K. R., Lucas, P. W., Prinz, J. F., \& Bruce, I. C. (1997). Mechanical properties of foods responsible for resisting food breakdown in the human mouth. Archives of Oral Biology, 42(1), 1-9.

Assad-Bustillos, M., Tournier, C., Septier, C., Della Valle, G., \& Feron, G. (2017). Relationships of oral comfort perception and bolus properties in the elderly with salivary flow rate and oral health status for two soft cereal foods. Food Research International, (September), 0-1.

Attenburrow, G. E., Goodband, R. M., Taylor, L. J., \& Lillford, P. J. (1989). Structure, mechanics and texture of a food sponge. Journal of Cereal Science, 9(1), IN170.

Besbes, E., Jury, V., Monteau, J. Y., \& Le Bail, A. (2013). Characterizing the cellular structure of bread crumb and crust as affected by heating rate using X-ray microtomography. Journal of Food Engineering, 115(3), 415-423.

Botula, Y.-D., Cornelis, W. M., Baert, G., Mafuka, P., \& Van Ranst, E. (2013). Particle size distribution models for soils of the humid tropics. Journal of Soils and Sediments, 13(4), 686-698. 
532 Bousquières, J., Michon, C., \& Bonazzi, C. (2017). Functional properties of cellulose 533 derivatives to tailor a model sponge cake using rheology and cellular structure $534 \quad$ analysis. Food Hydrocolloids, 70, 304-312.

535 Brooker, B. E. (1996). The role of fat in the stabilisation of gas cells in bread dough. $536 \quad$ Journal of Cereal Science, 24(3), 187-198.

537 Chen, J. (2009). Food oral processing-A review. Food Hydrocolloids, 23(1), 1-25.

538 Chen, J. (2014). Food oral processing: Some important underpinning principles of eating and sensory perception. Food Structure, 1(2), 91-105.

540 Chen, J. (2015). Food oral processing: Mechanisms and implications of food oral destruction. Trends in Food Science \& Technology, 45(2), 222-228.

542 Chen, J. (2016). Food for Elderly: Challenges and Opportunities. Journal of Texture $543 \quad$ Studies, 47(4), 255-256.

544 Chen, J., Khandelwal, N., Liu, Z., \& Funami, T. (2013). Influences of food hardness on the particle size distribution of food boluses. Archives of Oral Biology, 58(3), 293-298.

547 Devezeaux de Lavergne, M., Derks, J. A. M., Ketel, E. C., de Wijk, R. A., \& Stieger, M. (2015). Eating behaviour explains differences between individuals in dynamic

550 Devezeaux de Lavergne, M., van de Velde, F., \& Stieger, M. (2017). Bolus matters: the influence of food oral breakdown on dynamic texture perception. Food Funct., 8(2), 464-480.

553 Dewaest, M., Villemejane, C., Berland, S., Clément, J., Aliette, V., \& Michon, C. 554 (2017). Effect of crumb cellular structure characterized by image analysis on cake softness r o, (October), 1-11.

556 Esmaeelnejad, L., Siavashi, F., Seyedmohammadi, J., \& Shabanpour, M. (2016). The 
best mathematical models describing particle size distribution of soils. Modeling Earth Systems and Environment, 2(4), 166.

559

Feldkamp, L. A., Davis, L. C., \& Kress, J. W. (1984). Practical cone-beam algorithm. J. Opt. Soc. Am. A, 1(6), 612-619.

Fontijn-Tekamp, F. A., van der Bilt, A., Abbink, J. H., \& Bosman, F. (2004). Swallowing threshold and masticatory performance in dentate adults. Physiology \& Behavior, 83(3), 431-436.

Gallo, A., Giuberti, G., \& Masoero, F. (2016). Gas production and starch degradability of corn and barley meals differing in mean particle size. Journal of Dairy Science, 99(6), 4347-4359.

Gao, J., Ong, J. J. X., Henry, J., \& Zhou, W. (2017). Physical breakdown of bread and its impact on texture perception: A dynamic perspective. Food Quality and Preference, 60(May 2016), 96-104.

Gao, J., Tay, S. L., Koh, A. H.-S. S., \& Zhou, W. (2018). Dough and bread making from high- and low-protein flours by vacuum mixing: Part 3. Oral processing of bread. Journal of Cereal Science, 79, 408-417.

Gao, J., Wang, Y., Dong, Z., \& Zhou, W. (2017). Structural and mechanical characteristics of bread and their impact on oral processing: a review. International Journal of Food Science \& Technology, 1-15.

Gao, J., Wong, J. X., Lim, J. C.-S., Henry, J., \& Zhou, W. (2015). Influence of bread structure on human oral processing. Journal of Food Engineering, 167, 147-155.

Gibson, L.J.\& Ashby, M.F. (1997). Cellular solids, structure and properties. Cambridge Press University, $510 \mathrm{p}$.

Guessasma, S., \& Nouri, H. (2015). Comprehensive study of biopolymer foam compression up to densification using X-ray micro-tomography and finite 

element computation. European Polymer Journal, 72, 140-148.

583 Hedjazi, L., Martin, C. L., Guessasma, S., Della Valle, G., \& Dendievel, R. (2014). Experimental investigation and discrete simulation of fragmentation in expanded breakfast cereals. Food Research International, 55, 28-36.

\section{6}

Hibberd, G. E., \& Parker, N. S. (1985). Measurements of the Compression Properties of Bread Crumb. Journal of Texture Studies, 16(1), 97-110.

Hoebler, C., Devaux, M. F., Karinthi, A., Belleville, C., \& Barry, J. L. (2000). Particle size of solid food after human mastication and in vitro simulation of oral breakdown. International Journal of Food Sciences and Nutrition, 51(5), 353366.

Hoebler, C., Karinthi, A., Devaux, M.-F. F., Guillon, F., Gallant, D. J. G., Bouchet, B., ... Barry, J.-L. L. (1998). Physical and chemical transformations of cereal food during oral digestion in human subjects. The British Journal of Nutrition, 80(5), 429-436.

Jalabert-Malbos, M.-L., Mishellany-Dutour, A., Woda, A., \& Peyron, M.-A. (2007). Particle size distribution in the food bolus after mastication of natural foods. Food Quality and Preference, 18(5), 803-812.

Jourdren, S., Panouillé, M., Saint-Eve, A., Déléris, I., Forest, D., Lejeune, P., \& Souchon, I. (2016). Breakdown pathways during oral processing of different breads: impact of crumb and crust structures. Food \& Function, 7(3), 1446-57.

Jourdren, S., Saint-Eve, A., Panouillé, M., Lejeune, P., Déléris, I., \& Souchon, I. (2016). Respective impact of bread structure and oral processing on dynamic texture perceptions through statistical multiblock analysis. Food Research International, 87, 142-151.

Kansou, K., Chiron, H., Valle, G. Della, Ndiaye, A., Roussel, P., \& Shehzad, A. 

(2013). Modelling Wheat Flour Dough Proofing Behaviour: Effects of Mixing Conditions on Porosity and Stability. Food and Bioprocess Technology, 6(8), 2150-2164.

Kim, E. H. J., Corrigan, V. K., Wilson, A. J., Waters, I. R., Hedderley, D. I., \& Morgenstern, M. P. (2012). Fundamental fracture properties associated with sensory hardness of brittle solid foods. Journal of Texture Studies, 43(1), 49-62.

Laguna, L., Aktar, T., Ettelaie, R., Holmes, M., \& Chen, J. (2016). A Comparison Between Young and Elderly Adults Investigating the Manual and Oral Capabilities During the Eating Process. Journal of Texture Studies, 47(4), 361372.

Laguna, L., Sarkar, A., Artigas, G., \& Chen, J. (2015). A quantitative assessment of the eating capability in the elderly individuals. Physiology \& Behavior, 147, 274281.

Laguna, L., Sarkar, A., \& Chen, J. (2015). Assessment of eating capability of elderly subjects in UK: a quantitative evaluation. Proceedings of the Nutrition Society, 74(OCE2), E167.

Lassoued, N., Babin, P., Della Valle, G., Devaux, M. F., \& Réguerre, A. L. (2007). Granulometry of bread crumb grain: Contributions of 2D and 3D image analysis at different scale. Food Research International, 40(8), 1087-1097.

Le Bleis, F., Chaunier, L., Della Valle, G., Panouillé, M., \& Réguerre, A. L. (2013). Physical assessment of bread destructuration during chewing. Food Research International, 50(1), 308-317.

Le Bleis, F., Chaunier, L., Montigaud, P., \& Della Valle, G. (2016). Destructuration mechanisms of bread enriched with fibers during mastication. Food Research International, 80, 1-11. 
Lucas, P. W., \& Luke, D. A. (1983). Computer simulation of the breakdown of carrot particles during human mastication. Archives of Oral Biology, 28(9), 821-826.

Lucas, P. W., Prinz, J. F., Agrawal, K. R., \& Bruce, I. C. (2002). Food physics and oral physiology. Food Quality and Preference, 13(4), 203-213.

Mihai, L. A., \& Goriely, A. (2015). Finite deformation effects in cellular structures with hyperelastic cell walls. International Journal of Solids and Structures, 53, 107128.

Mohammed, M. A. P., Tarleton, E., Charalambides, M. N., \& Williams, J. G. (2013). Mechanical characterization and micromechanical modeling of bread dough. Journal of Rheology, 57(1), 249-272.

Olthoff, L. W., Van Der Bilt, A., Bosman, F., \& Kleizen, H. H. (1984). Distribution of particle sizes in food comminuted by human mastication. Archives of Oral Biology, 29(11), 899-903.

Panouillé, M., Saint-Eve, A., Déléris, I., Le Bleis, F., \& Souchon, I. (2014). Oral processing and bolus properties drive the dynamics of salty and texture perceptions of bread. Food Research International, 62, 238-246.

Panouillé, M., Saint-Eve, A., \& Souchon, I. (2016). Instrumental methods for bolus characterization during oral processing to understand food perceptions. Current Opinion in Food Science, 9, 42-49.

Pascua, Y., Koç, H., \& Foegeding, E. A. (2013). Food structure: Roles of mechanical properties and oral processing in determining sensory texture of soft materials. Current Opinion in Colloid \& Interface Science, 18(4), 324-333.

Peleg, M. (1993). Tailoring texture for the elderly: Theoretical aspects and technological options. Critical Reviews in Food Science and Nutrition, 33(1), 4555. 
657 Pentikäinen, S., Sozer, N., Närväinen, J., Ylätalo, S., Teppola, P., Jurvelin, J., ...

658 Poutanen, K. (2014). Effects of wheat and rye bread structure on mastication 659 process and bolus properties. Food Research International, 66, 356-364.

660 Peyron, M.-A., Gierczynski, I., Hartmann, C., Loret, C., Dardevet, D., Martin, N., \& 661 Woda, A. (2011). Role of Physical Bolus Properties as Sensory Inputs in the $662 \quad$ Trigger of Swallowing. PLoS ONE, 6(6), e21167.

663 Peyron, M.-A., Mishellany, A., \& Woda, A. (2004). Particle Size Distribution of Food 664 Boluses after Mastication of Six Natural Foods. Journal of Dental Research, 665 $83(7), 578-582$.

666 Peyron, M. A., Woda, A., Bourdiol, P., \& Hennequin, M. (2017). Age-related changes 667 in mastication. Journal of Oral Rehabilitation, 44(4), 299-312.

668 Prinz, J. F., \& Lucas, P. W. (1997). An optimization model for mastication and 669 swallowing in mammals. Proceedings of the Royal Society of London B: Biological Sciences, 264(1389).

671 Rodrigues, S. A., Young, A. K., James, B. J., \& Morgenstern, M. P. (2014). Structural changes within a biscuit bolus during mastication. Journal of Texture Studies, 45(2), 89-96.

674

Scanlon, M. G., \& Zghal, M. C. (2001). Bread properties and crumb structure. Food Research International, 34(10), 841-864.

Schwartz, C., Vandenberghe-Descamps, M., Sulmont-Rossé, C., Tournier, C., \& Feron, G. (2017). Behavioral and physiological determinants of food choice and consumption at sensitive periods of the life span, a focus on infants and elderly.

680 Serra, J. P. (1982). Image analysis and mathematical morphology. Academic Press. 681 Retrieved from https://books.google.co.uk/books?id=6pZTAAAAYAAJ 
682

683

684

685

686

687

688

689

690

691

692

693

694

695

696

697

698

699

700

701

702

703

704

705

706

Ship, J. A. (1999). The Influence of Aging on Oral Health and Consequences for Taste and Smell. Physiology \& Behavior, 66(2), 209-215.

Sozer, N., Dogan, H., \& Kokini, J. L. (2011). Textural properties and their correlation to cell structure in porous food materials. Journal of Agricultural and Food Chemistry, 59(5), 1498-1507.

United Nations Department of Economic and Social Affairs. (2002). World population ageing, 1950-2050. Retrieved July 27, 2017, from http://www.un.org/esa/population/publications/worldageing19502050/

van der Bilt, A., Olthoff, L. W., van der Glas, H. W., van der Weelen, K., \& Bosman, F. (1987). A mathematical description of the comminution of food in human mastication. Archives of Oral Biology, 32(8), 579-588.

van der Glas, H. W., Kim, E. H. J., Mustapa, A. Z., \& Elmanaseer, W. R. (2018). Selection in mixtures of food particles during oral processing in man. Archives of Oral Biology, 85(August 2017), 212-225.

van der Glas, H. W., van der Bilt, A., \& Bosman, F. (1992). A selection model to estimate the interaction between food particles and the post-canine teeth in human mastication. Journal of Theoretical Biology, 155(1), 103-120.

Van Dyck, T., Verboven, P., Herremans, E., Defraeye, T., Van Campenhout, L., Wevers, M., ... Nicolaï, B. (2014). Characterisation of structural patterns in bread as evaluated by X-ray computer tomography. Journal of Food Engineering, 123, $67-77$.

Vandenberghe-Descamps, M., Labouré, H., Prot, A., Septier, C., Tournier, C., Feron, G., \& Sulmont-Rossé, C. (2016). Salivary Flow Decreases in Healthy Elderly People Independently of Dental Status and Drug Intake. Journal of Texture Studies, 47(4), 353-360. 
707 Wang, S., Austin, P., \& Bell, S. (2011). It's a maze: The pore structure of bread 708 crumbs. Journal of Cereal Science, 54(2), 203-210.

709 Witt, T., \& Stokes, J. R. (2015). Physics of food structure breakdown and bolus 710 formation during oral processing of hard and soft solids. Current Opinion in Food 711 Science, 3, 110-117.

712 Young, A. K., Cheong, J. N., Hedderley, D. I., Morgenstern, M. P., \& James, B. J.

713 (2013). Understanding the link between bolus properties and perceived texture.

$714 \quad$ Journal of Texture Studies, 44(5), 376-386.

715 Yven, C., Guessasma, S., Chaunier, L., Della Valle, G., \& Salles, C. (2010). The role 716 of mechanical properties of brittle airy foods on the masticatory performance.

717 Journal of Food Engineering, 101(1), 85-91.

718 


\section{List of Figures}

721 Fig.1: (a) Crumb cross-sections and (b) 2D (top), 3D (bottom) images of sponge

722 cake and brioche (diameter $=20 \mathrm{~mm}$ ) obtained by micro-computed tomography (XR-

$723 \mu \mathrm{CT}$ ) and (c) the resulting cumulated size distribution of walls (dotted line) and cells

724 (continuous line) for sponge-cake (blue) and brioche (red).

725 Fig.2: Average stress-strain curves obtained by uniaxial compression of the two 726 cereal foods: sponge-cake (blue) and brioche (red). Error bars reflect the standard 727 deviation obtained from 5 replicates.

728 Fig.3: Examples of cumulative size distribution curves of bolus particles for the three 729 chewing time values C1 (blue), C2 (red) and SP (green), and their corresponding 730 fitting by Gompertz model (dotted lines), for sponge cake (a) and, in the case of 731 brioche, for the three patterns of fragmentation / agglomeration, I, II and III 732 respectively (b, c, d).

733 Fig.4: Variations of median particle size $\left(D_{50}\right)$ and interquartile ratio $\left(D_{75} / D_{25}\right)$ with 734 chewing time for sponge-cake ( $a$, blue) and brioche (b, red). Empty symbols: 735 satisfactory dental status, filled symbols: poor dental status.

736 Fig. 5: Variations of $c$ and b values derived from Gompertz model with respectively 737 (a) particle median size $\left(D_{50}\right)$ and (b) interquartile ratio $\left(D_{75} / D_{25}\right)$ for sponge cake 738 (blue) and brioche (red).

739 Fig.6: Typical examples of boli images after chewing at C1 (left), C2 (center) and at 740 swallowing point (right) for sponge-cake (a), and for brioche, decreasing size (case I)

741 (b), increasing size (case II) (c), combination of both (case III) (d). These images 


\section{$745 \quad$ List of Tables}

746 Table 1. Structural and mechanical product properties.

747 Table 2. Gompertz model fitting parameters for particle size distributions of products 748 per chewing sequence. 


\section{List of Tables}

Table 1. Structural and mechanical product properties.

Table 2. Gompertz model fitting parameters for particle size distributions of products per chewing sequence.

\section{List of Figures}

Fig.1: (a) Crumb cross-sections and (b) 2D (top) , 3D (bottom) images of sponge cake and brioche (diameter $=20 \mathrm{~mm}$ ) obtained by micro-computed tomography (XR$\mu \mathrm{CT}$ ) and (c) the resulting cumulated size distribution of walls (dotted line) and cells (continuous line) for sponge-cake (blue) and brioche (red).

Fig.2: Average stress-strain curves obtained by uniaxial compression of the two cereal foods: sponge-cake (blue) and brioche (red). Error bars reflect the standard deviation obtained from 5 replicates.

Fig.3: Examples of cumulative size distribution curves of bolus particles for the three chewing time values C1 (blue), C2 (red) and SP (green), and their corresponding fitting by Gompertz model (dotted lines), for sponge cake (a) and, in the case of brioche, for the three patterns of fragmentation / agglomeration, I, II and III respectively (b, c, d).

Fig.4: Variations of median particle size $\left(D_{50}\right)$ and interquartile ratio $\left(D_{75} / D_{25}\right)$ with chewing time for sponge-cake ( $a$, blue) and brioche (b, red). Empty symbols: satisfactory dental status, filled symbols: poor dental status.

Fig. 5: Variations of $c$ and $b$ values derived from Gompertz model with respectively (a) particle median size $\left(D_{50}\right)$ and (b) interquartile ratio $\left(D_{75} / D_{25}\right)$ for sponge cake (blue) and brioche (red).

Fig.6: Typical examples of boli images after chewing at C1 (left), C2 (center) and at swallowing point (right) for sponge-cake (a), and for brioche, decreasing size (case I) (b), increasing size (case II) (c), combination of both (case III) (d). These images correspond to the size distributions plotted in Fig.3. 


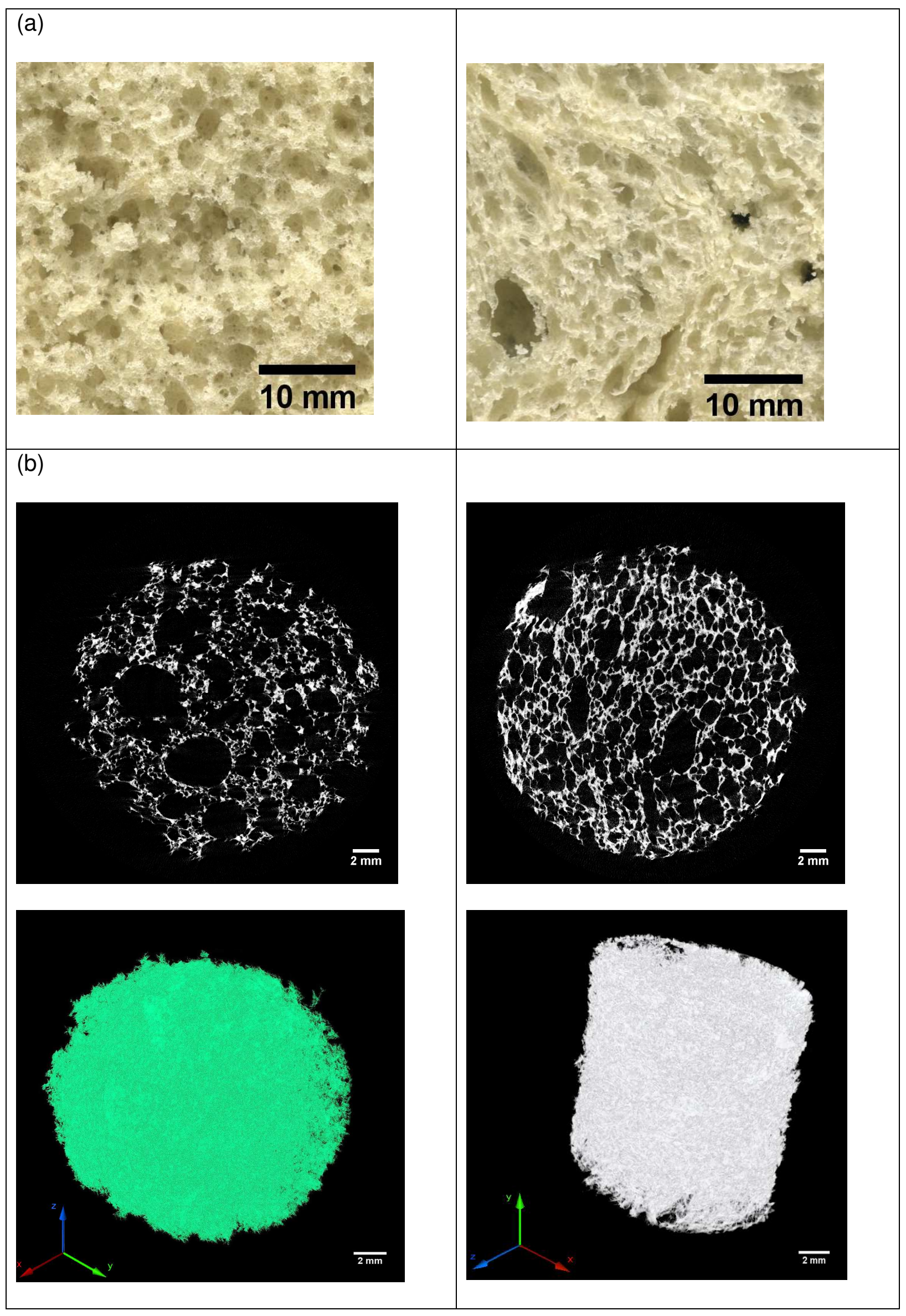



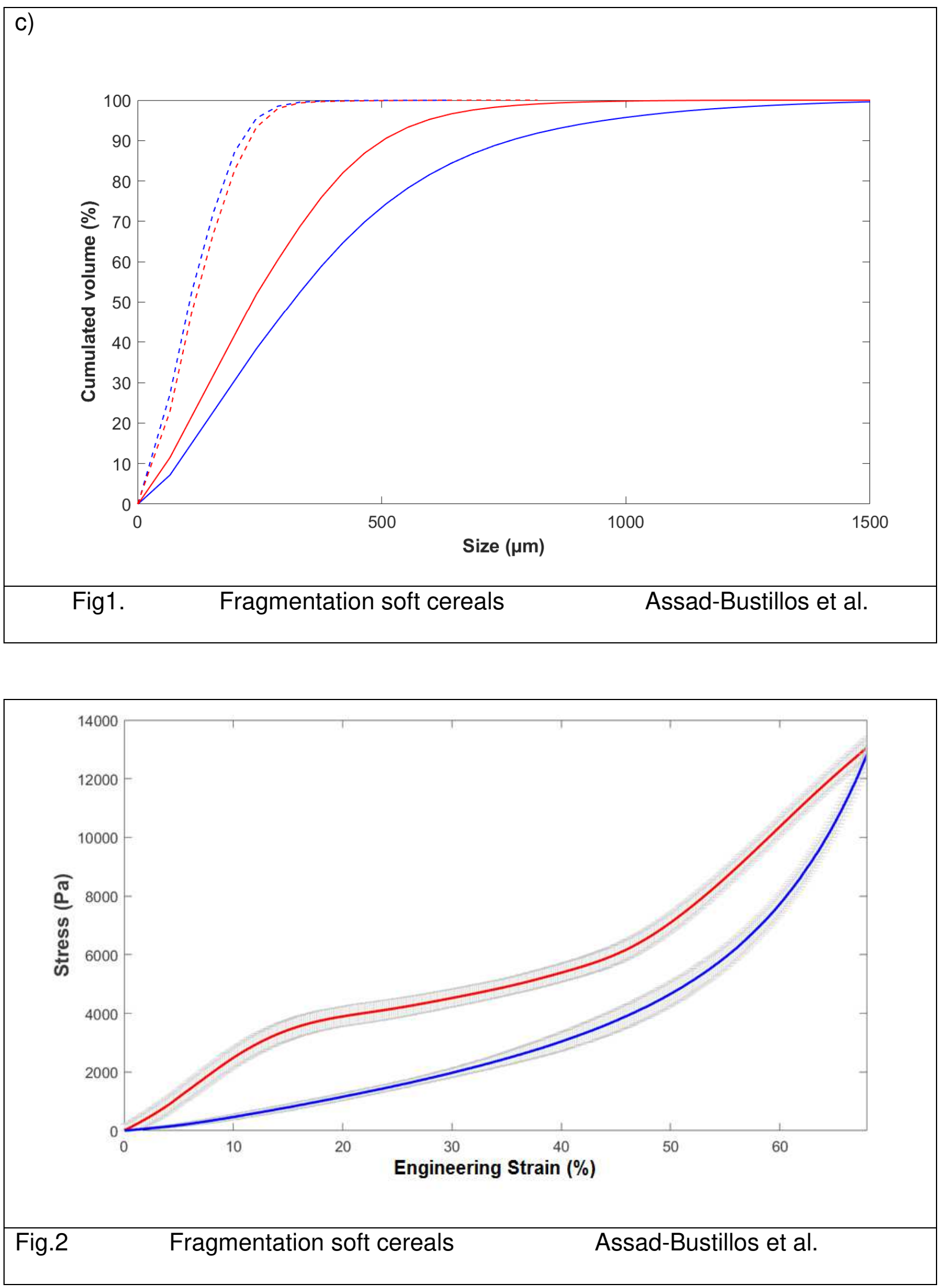
(a)

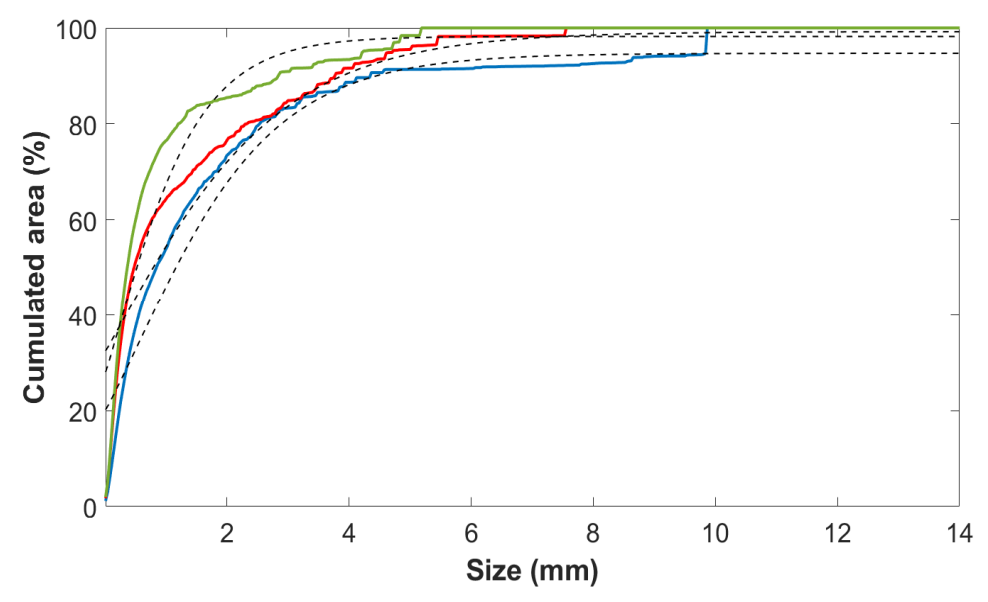

(c)

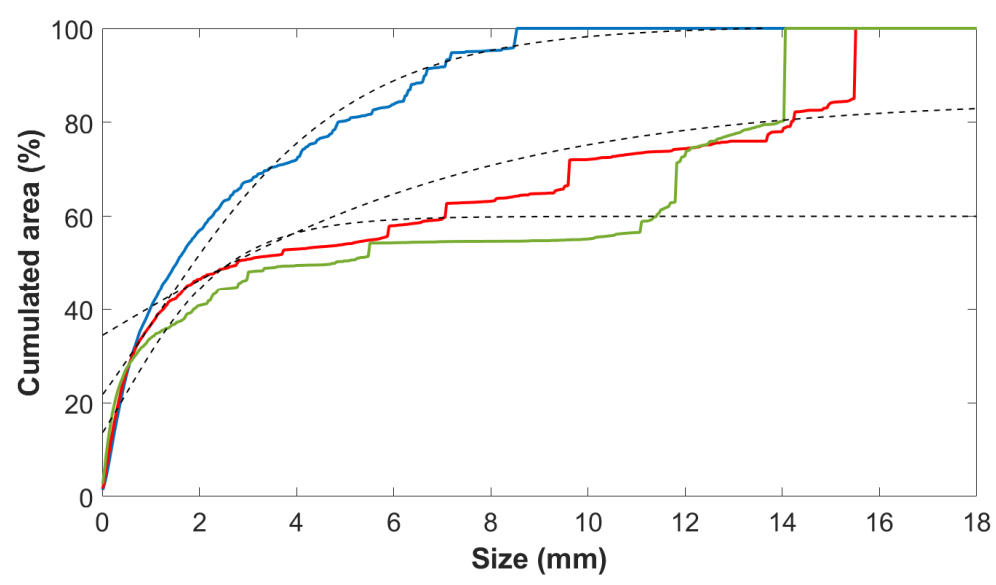

(b)

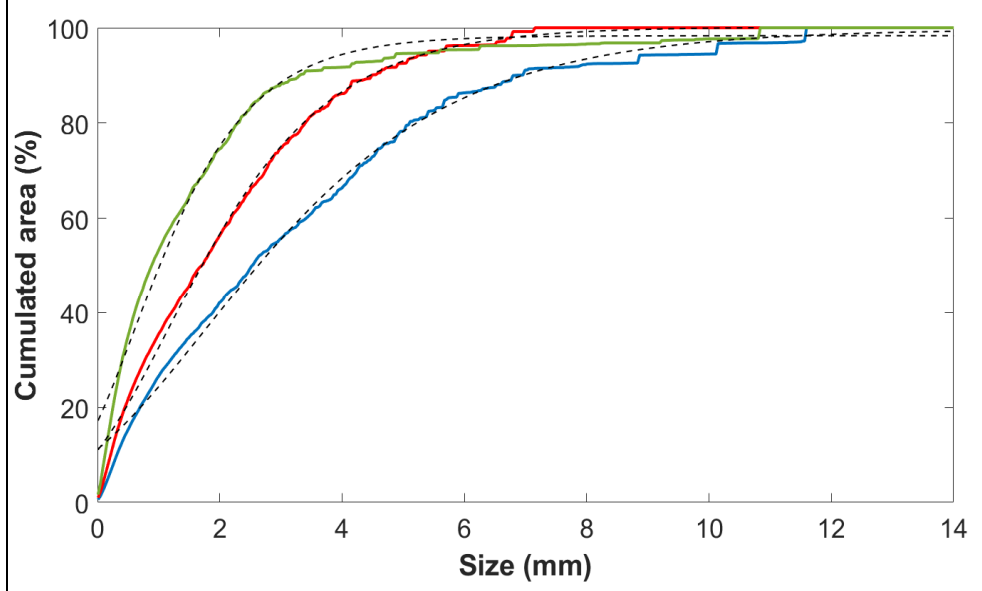

(d)

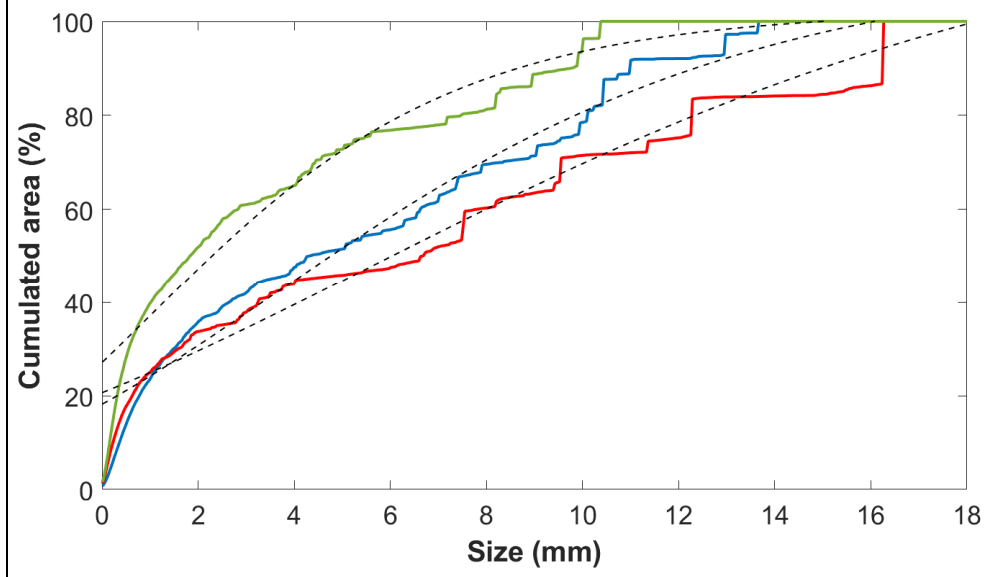

Fig.3 Fragmentation soft cereals

Assad-Bustillos et al. 


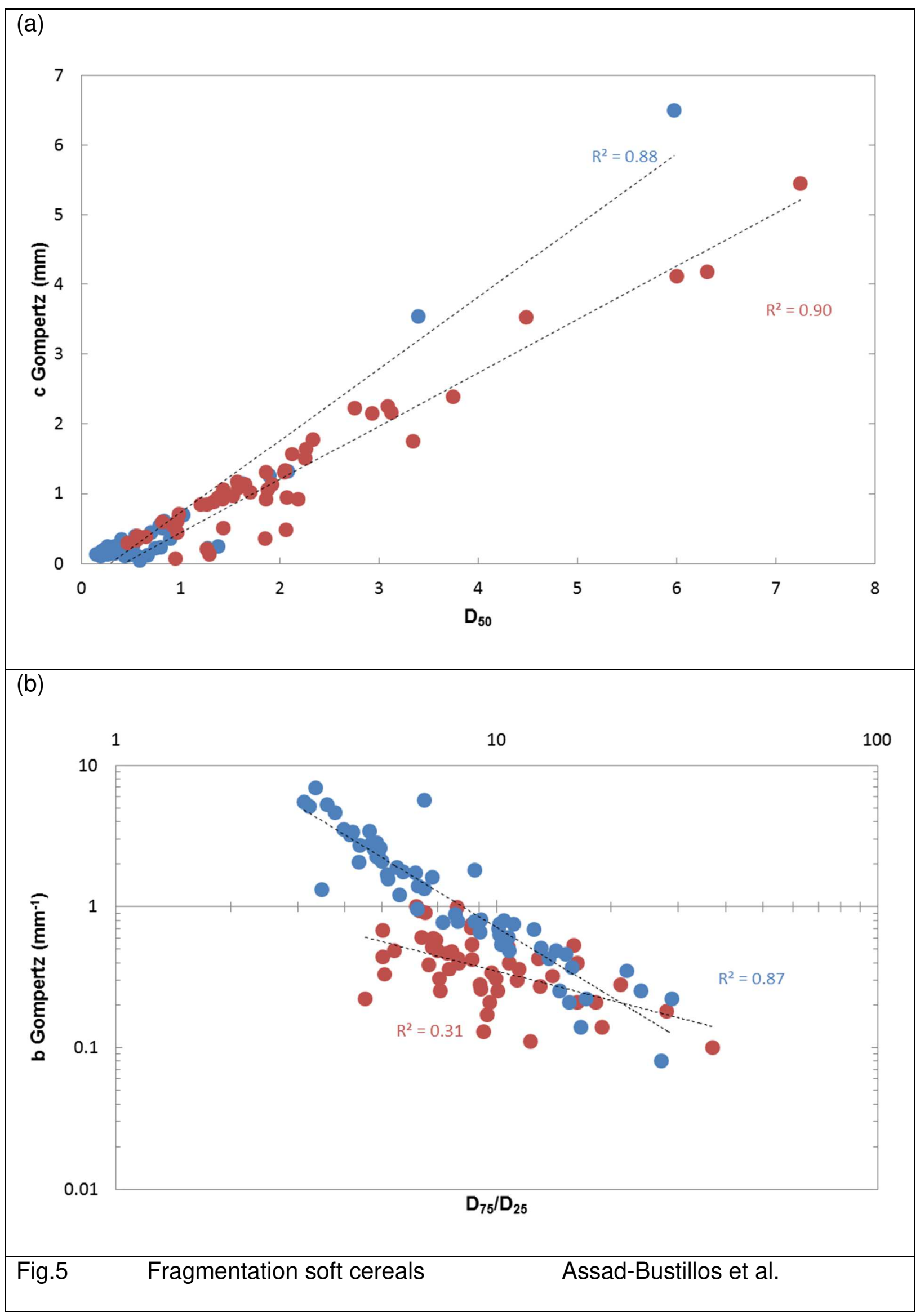




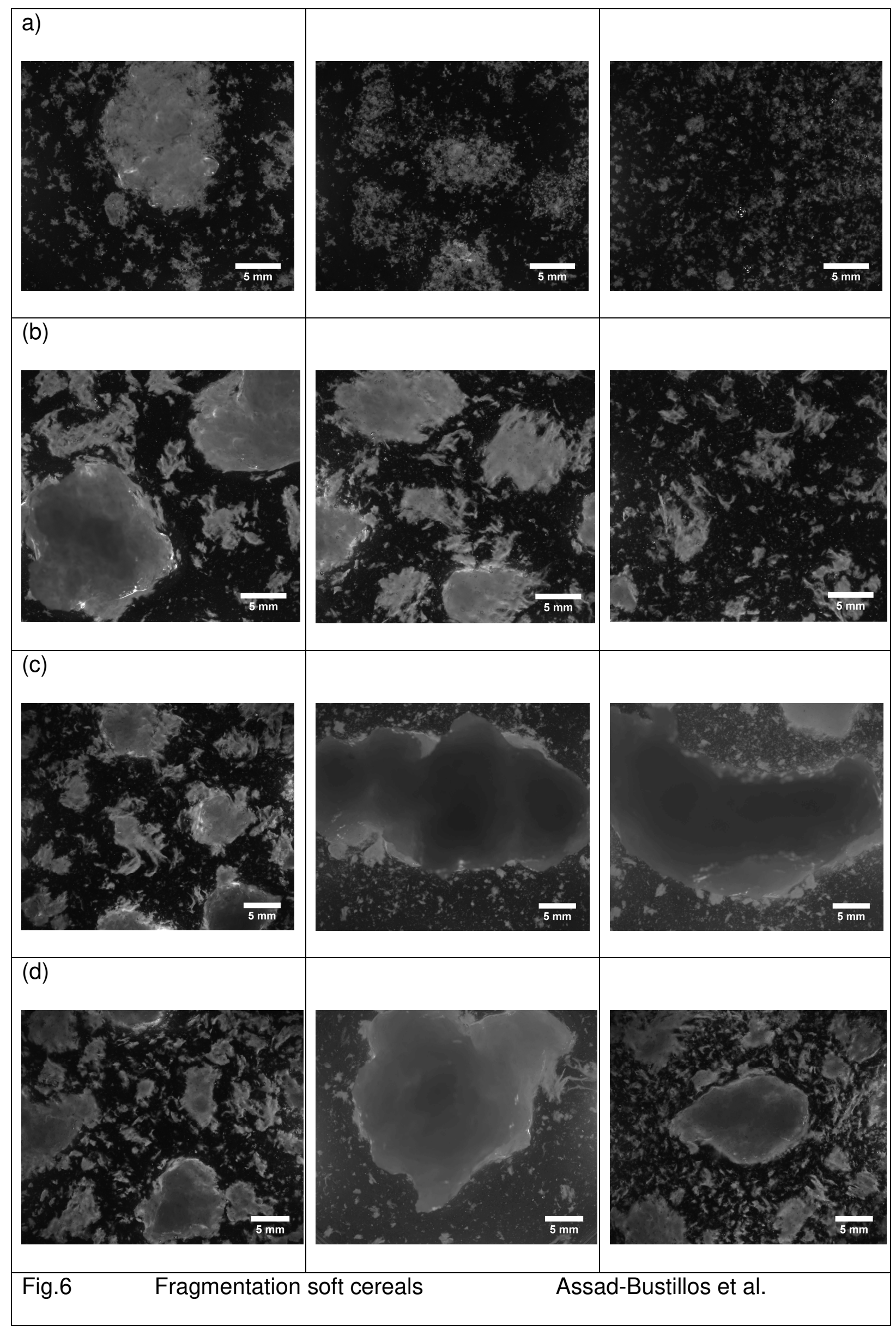




\begin{tabular}{|lcc|}
\hline & Sponge-cake & Brioche \\
\hline Direct Measures & & \\
Density $\left(\mathrm{g} / \mathrm{cm}^{3}\right)$ & $0.21( \pm 0.02)^{\mathrm{A}}$ & $0.33( \pm 0.02)^{\mathrm{B}}$ \\
Young's modulus E (kPa) & $5( \pm 1)^{\mathrm{A}}$ & $20( \pm 3)^{\mathrm{B}}$ \\
Critical stress $\sigma_{\mathrm{c}}(\mathrm{kPa})$ & $\mathrm{N} / \mathrm{A}$ & $3( \pm 1)$ \\
3D Image Analysis & & \\
Porosity & $0.79( \pm 0.01)^{\mathrm{B}}$ & $0.69( \pm 0.04)^{\mathrm{A}}$ \\
Relative density (D) & $0.21( \pm 0.01)^{\mathrm{A}}$ & $0.31( \pm 0.04)^{\mathrm{B}}$ \\
Wall Size & & \\
\multicolumn{1}{|c}{$\mathrm{D}_{25}$} & $41( \pm 1)^{\mathrm{A}}$ & $45( \pm 1)^{\mathrm{B}}$ \\
$\mathrm{D}_{50}$ & $99( \pm 1)^{\mathrm{A}}$ & $118( \pm 5)^{\mathrm{A}}$ \\
$D_{75}$ & $176( \pm 1)^{\mathrm{A}}$ & $200( \pm 12)^{\mathrm{A}}$ \\
Cell size & & \\
$D_{25}$ & $95( \pm 1)^{\mathrm{B}}$ & $73( \pm 10)^{\mathrm{A}}$ \\
$D_{50}$ & $296( \pm 2)^{\mathrm{B}}$ & $197( \pm 26)^{\mathrm{A}}$ \\
$D_{75}$ & $785( \pm 81)^{\mathrm{B}}$ & $403( \pm 40)^{\mathrm{A}}$ \\
\hline
\end{tabular}

${ }^{*}$ Values are average of $n=5$ measures ( \pm Std. deviation).

** Values are average of $n=2$ measures ( \pm Std. deviation).

Different letters $(A, B)$, indicate means that significantly $(p<0.05)$ differ between products (StudentNewman-Keuls test). 
Table 2. Fragmentation soft cereals

Assad-Bustillos et al.

\begin{tabular}{|c|c|c|c|c|}
\hline \multirow{2}{*}{ Product } & \multirow{2}{*}{ Parameter } & \multicolumn{3}{|c|}{ Chewing sequence } \\
\hline & & C1 & C2 & $S P$ \\
\hline \multirow{5}{*}{ Sponge-cake } & $\mathrm{D}_{50}$ & $1.1( \pm 1.3)^{\mathrm{a} A}$ & $0.5( \pm 0.7)^{\mathrm{bA}}$ & $0.3( \pm 0.1)^{\mathrm{CA}}$ \\
\hline & $D_{75} / D_{25}$ & $13.3( \pm 6.1)^{\mathrm{a} A}$ & $8.9( \pm 5.7)^{\mathrm{b} \mathrm{A}}$ & $5.0( \pm 2.1)^{\mathrm{CA}}$ \\
\hline & a & $100.8( \pm 12.6)^{\mathrm{aA}}$ & $100.4( \pm 7.6)^{\mathrm{aA}}$ & $99.3( \pm 0.5)^{\mathrm{aA}}$ \\
\hline & b & $0.7( \pm 0.5)^{\mathrm{aA}}$ & $1.4( \pm 1.2)^{\mathrm{b} \mathrm{A}}$ & $2.7( \pm 1.6)^{\mathrm{CA}}$ \\
\hline & c & $0.7( \pm 1.5)^{\mathrm{aA}}$ & $0.3( \pm 0.9)^{\mathrm{b} \mathrm{A}}$ & $0.2( \pm 0.1)^{\mathrm{CA}}$ \\
\hline \multirow{5}{*}{ Brioche } & $\mathrm{D}_{50}$ & $2.5( \pm 1.5)^{\mathrm{a} B}$ & $2.5( \pm 2.3)^{\mathrm{a} B}$ & $2.9( \pm 4.0)^{\mathrm{a} B}$ \\
\hline & $D_{75} / D_{25}$ & $8.3( \pm 3.4)^{\mathrm{a} B}$ & $15.2( \pm 14.4)^{\mathrm{aB}}$ & $25.6( \pm 24.2)^{\mathrm{b} B}$ \\
\hline & a & $108.7( \pm 39.4)^{\mathrm{a} \mathrm{A}}$ & $106.7( \pm 28.3)^{\mathrm{a} A}$ & $102.2( \pm 10.1)^{\mathrm{a} A}$ \\
\hline & b & $0.4( \pm 0.1)^{\mathrm{a} B}$ & $0.4( \pm 0.2)^{\mathrm{a} B}$ & $0.5( \pm 0.3)^{a \mathrm{~B}}$ \\
\hline & c & $2.4( \pm 3.7)^{\mathrm{a} B}$ & $1.9( \pm 3.0)^{\mathrm{a} B}$ & $-0.3( \pm 3.4)^{\mathrm{b} \mathrm{A}}$ \\
\hline
\end{tabular}

Note: All values are means ( \pm Std. deviation) of $n=20$ subjects. The negative mean value of $c$ for brioche bolus at SP means that many small particles have a size value below image resolution.

Different letters $(a, b, c)$ indicate means that significantly $(p<0.05)$ differ between chewing sequences (Student-Newman-Keuls test).

Different letters $(A, B)$, indicate means that significantly $(p<0.05)$ differ between products (StudentNewman-Keuls test). 
(a)
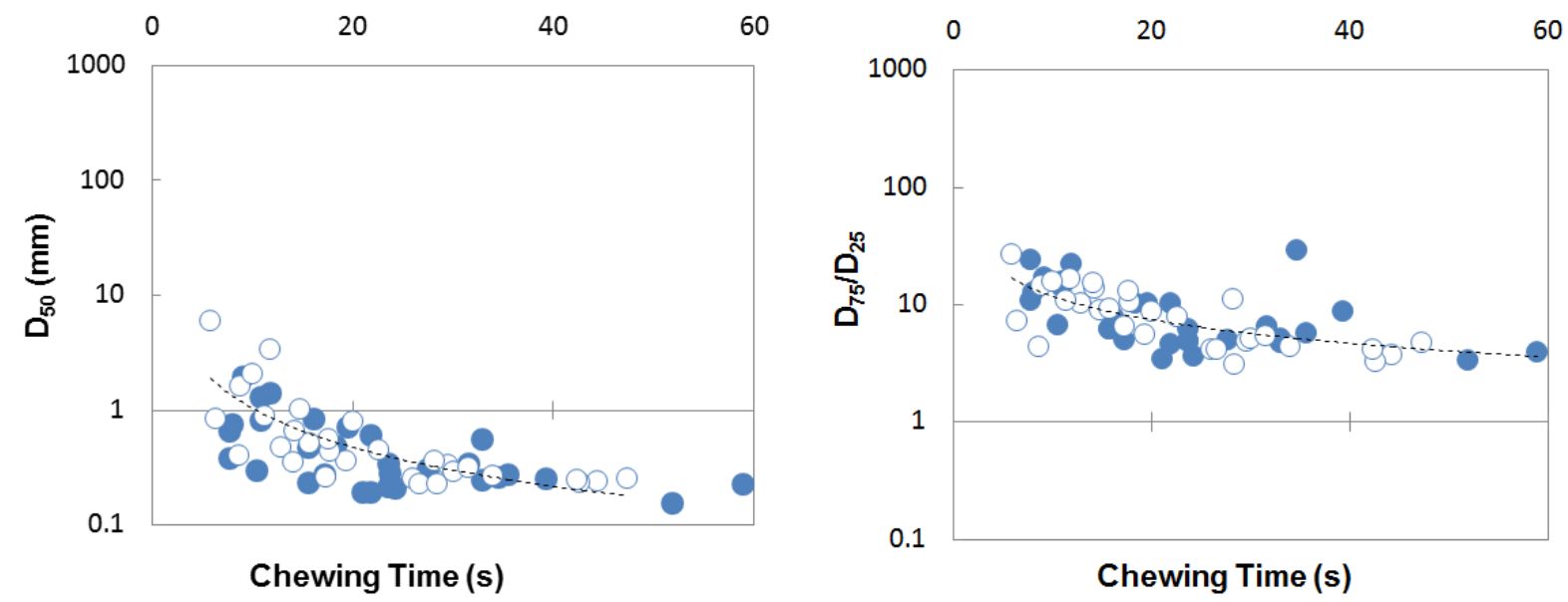

(b)
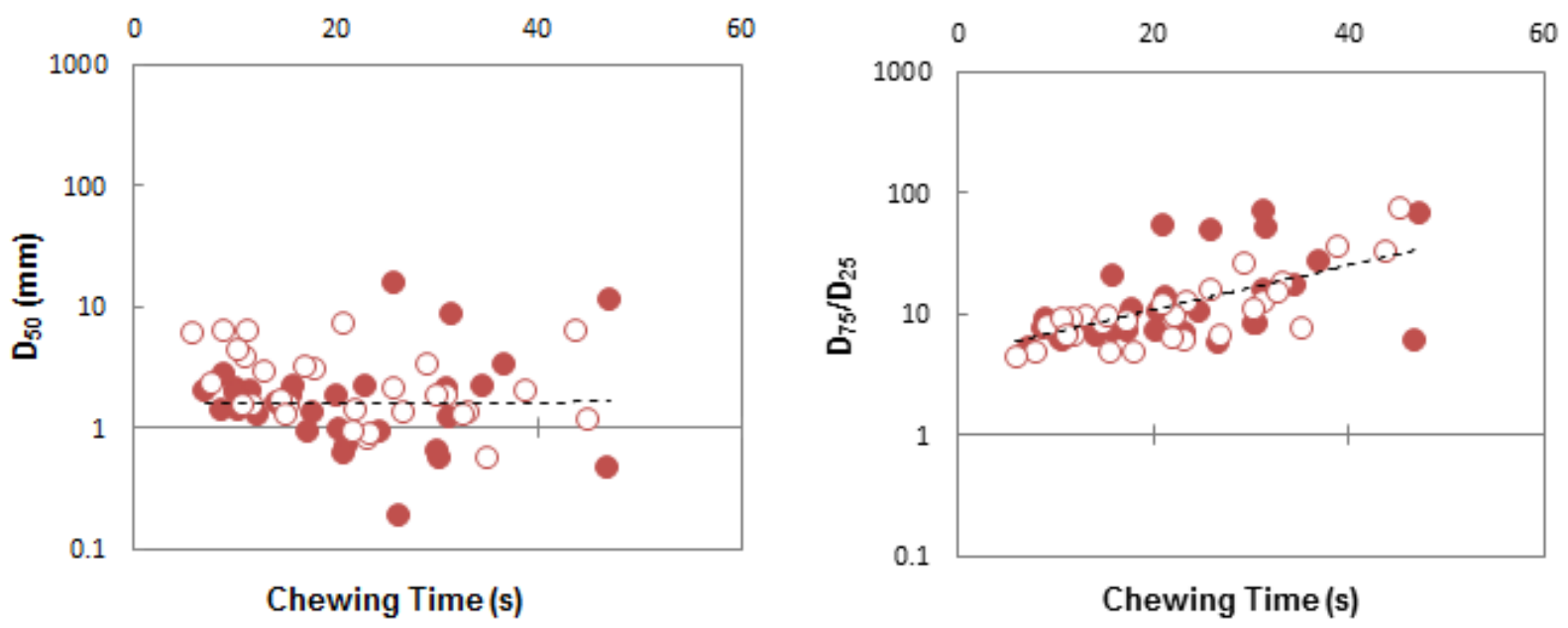

Fig.4 Fragmentation soft cereals Assad-Bustillos et al. 


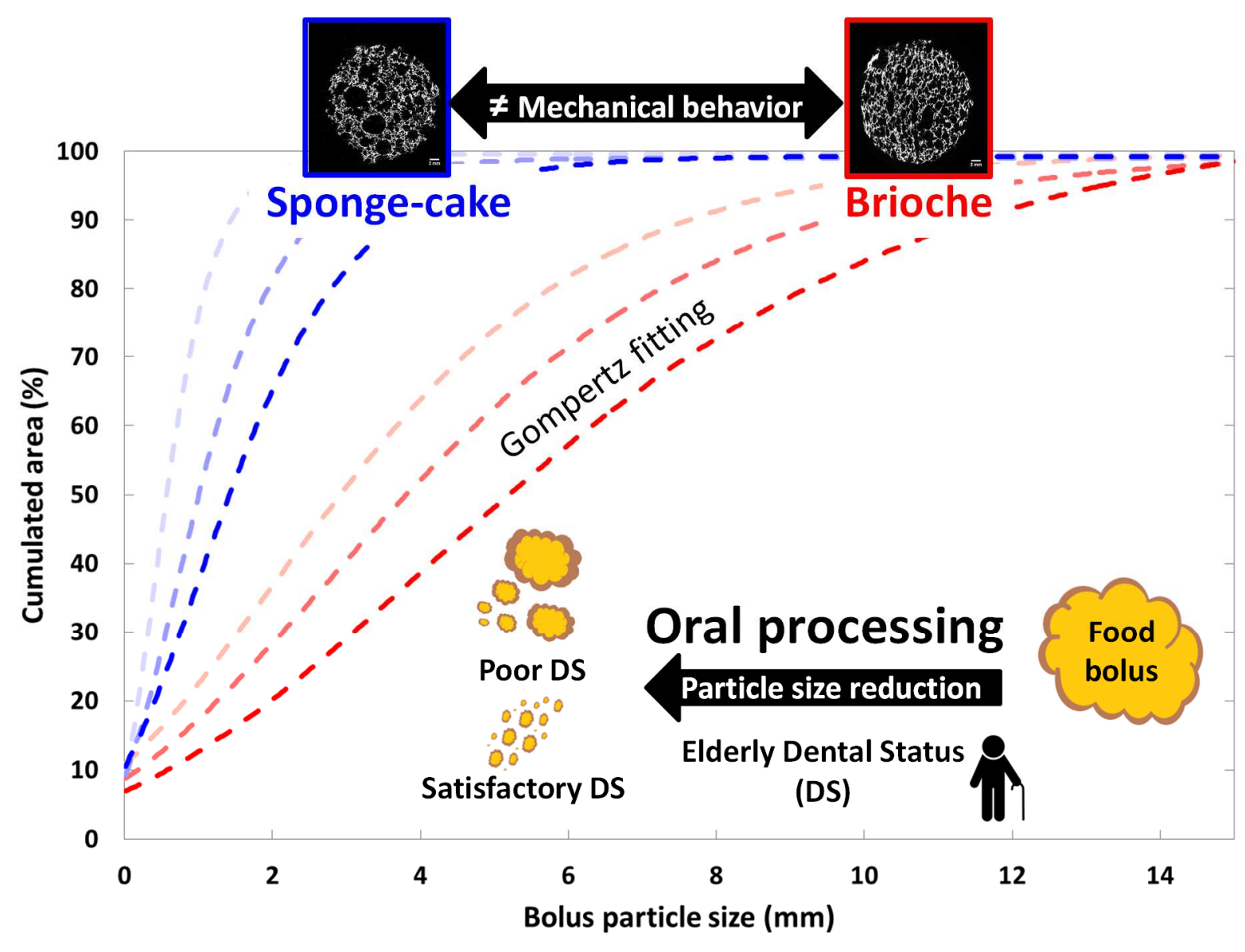

Graphical Abstract for “Cereal FOP fragmentation” by Assad-Bustillos et al.:

The mechanisms of fragmentation of soft cereal foods during chewing are determined by image analysis and by fitting particle size distributions. This approach has allowed us to link food structure and mechanical behavior on one side, with the dental status of elderly on the other side. 